\title{
SIGNIFICADOS SOCIAIS DO INGLIDING DE VOGAIS TÔNICAS NO PORTUGUÊS FALADO EM PORTO AlegRE (RS)
}

\section{Elisa Battisti ${ }^{\star}$ Samuel Gomes de Oliveira ${ }^{\star \star}$}

Resumo: Este artigo trata dos significados sociais do ingliding de vogais tônicas (voc[e] voc[en], aqu[i] aqu[iol) no português falado em Porto Alegre (RS), na linha de Eckert (2008). A análise revela que essa variável sociolinguística é recrutada para indexar estilos e certos significados sociais (descolado, descontraido, desencanado, preguiçoso, com sotaque, morador da área central da cidade), constituidores de um campo indexical fluido, passivel de (re)interpretação a cada uso da linguagem.

Palavras-chave: Variação linguística. Ingliding. Campo indexical.

\section{INTRODUÇÃo}

R ealizar entrevistas sociolinguísticas em uma grande cidade brasileira como Porto Alegre (RS) - territorialmente ampla, com uma população estimada em mais de um milhão, quatrocentos mil habitantes em $2015^{1}$ - e garantir que a amostra de fala seja representativa exige identificar elementos da sócio-história e da organização social e linguística da comunidade que fundamentem a estratificação. Envolvidos nessa tarefa há algum tempo e tendo contemplado, na investigação, a percepção dos falantes (PRESTON, 1989) sobre possiveis diferenças no português dessa comunidade, identificamos uma variável da fala porto-alegrense com algum grau de consciência social. 
Este artigo é sobre essa variável, não sobre a estratificação da amostra em si. A variável em questão é a realização alongada e ditongada de vogais tônicas, como em voc[e] voc[ee], aqu[i] aqu[ie], av[o] av[oe], t[u]do t[ue]do, a que temos denominado ingliding (BATTISTI, 2013; BATTISTI; OLIVEIRA, 2014; OLIVEIRA, 2015). Nem todos os porto-alegrenses produzem ingliding, e o grau de consciência da variável é diferente, dependendo do grupo social considerado. Indivíduos que não pertencem à comunidade de fala de Porto Alegre selecionam o ingliding como um estereótipo (LABOV, 2008 [1972]), isto é, uma variável sujeita a comentários, presente em imitações de um tipo humano específico, o magrão porto-alegrense (BATTISTI, 2013). Já para os porto-alegrenses, a variável é um marcador (LABOV, 2008 [1972]), pois, embora não apresente o mesmo nível de consciência social do estereótipo, parece colaborar na composição de um estilo (OLIVEIRA, 2015).

A análise que fazemos neste artigo avança na investigação do ingliding no português falado em Porto Alegre e explora os significados sociais da variável na perspectiva dinâmica de Eckert (2008), guiada pela ideia de que variantes são recursos para a construção de significados sociais em práticas estilísticas. Retomam-se resultados de Oliveira (2015), de percepção e avaliação do ingliding, para propor um campo indexical de significados potenciais da variável, ativados no uso situado da linguagem (produção linguística) e mobilizados na reação emocional-afetiva a esse uso (percepção/atitude linguística).

\section{Ingliding De vogais tônicas No PORTuguês falado em PoRTo Alegre}

Ingliding é a transformação de uma vogal simples em um ditongo com glide centralizado. De acordo com Donegan (1978, p. 107), nos ditongos decrescentes resultantes de ingliding, um glide se cria pela perda de tensão e abaixamento da vogal ao final de sua produção.

Na introdução do ANAE (The Atlas of North American English - Atlas do Inglês Norte-Americano), Labov, Ash e Boberg (2006) explicam que ingliding distingue-se da ditongação porque a ditongação cria glides altos. Já o ingliding caracteriza-se pela criação, em inglês, de glides nem altos, nem baixos: a língua distancia-se dos pontos periféricos (anterior e posterior) no espaço vocálico e a articulação vocálica se centraliza. A Figura 1 ilustra a centralização e a criação de um glide um pouco mais baixo que o do inglês, similar em qualidade à vogal [e], correspondente ao verificado em nossos dados, de português falado em Porto Alegre. 
DOSSIE

VOGAIS

Alta Anterior

Figura 1 - Centralização vocálica no processo de ingliding, com exemplos

Fonte: Elaborada pelos autores.

Battisti (2013) constatou que o ingliding não resulta de ditongação assimilatória (como três>treis, faz>faiz). Trata-se de um processo fonético não determinado coarticulatoriamente, que resulta em uma estrutura de contorno. Ocorre principalmente com seis das sete vogais que se realizam em sílabas tônicas no português (sendo /a/ a vogal que parece não emergir com ingliding) e pode ter motivação entoacional.

\section{Aspectos acústicos e entoacionais}

No estereótipo da fala porto-alegrense com ingliding, referido no primeiro parágrafo da Introdução, é recorrente a menção a comunicadores de rádio e apresentadores de televisão como sujeitos em cuja fala se verifica essa realização. Em Battisti e Oliveira (2014), analisamos acusticamente dados de uma comunicadora de rádio porto-alegrense de 55 anos, tomada como protótipo do padrão com ingliding. Usando o software PRAAT ${ }^{2}$, analisamos contextos de vogais em sílaba tônica com obstruintes ou pausas nas bordas, o que permite visualizar de forma inequívoca o início e o final da emissão vocálica nos espectrogramas. A centralização que ocorre no ingliding é captada medindo-se os valores de $\mathrm{F}_{2}$ na análise fonética acústica ${ }^{3}$. Obtivemos medidas de duração (absoluta, em milissegundos) das vogais e medidas de $\mathrm{F}_{2}$ (inicial e final das vogais) em $\mathrm{Hertz}^{4}$. Comparamos as medidas de vogais que, de oitiva, soavam ditongadas com realiza-

\footnotetext{
PRAAT é um programa computacional para análise acústica desenvolvido por Paul Boersma e David Weenik, da Universidade de Amsterdã. Disponível em: <http://www.fon.hum.uva.nl/praat/>. Acesso em: 9 abr. 2016.

3 F1 e F2 são rótulos de primeiro e segundo formantes, respectivamente. Na análise fonética acústica de segmentos da fala, formantes são as frequências de ressonância do trato vocal, rotuladas F1, F2, F3 etc., a partir da frequência de ressonância mais baixa (JOHNSON, 2012 p. 44). Com a medida em Hertz ( $\mathrm{Hz}$ ) de F1, verifica-se a altura de uma vogal; com a medida de F2, sua anterioridade/posterioridade.

4 As medidas de F1, apesar de feitas, não foram incluídas no estudo de Battisti e Oliveira (2014). Deu-se preferência às medidas de F0 e F2, necessárias à representação integrada de fonética e fonologia do ingliding, para a análise feita pelos autores conforme Clements e Hertz (1996).
} 
ções que aparentemente não sofriam o processo. Fizemos análise de $\mathrm{F}_{0}(\text { pitch })^{5}$ de apenas alguns dados, elucidativos das realizações em questão como manifestações de eventos tonais marcadores de constituintes prosódicos.

A análise da curva de $\mathrm{F}_{2}$ de 376 vogais em sílaba tônica comprovou mudança de valores (diferença entre $\mathrm{F}_{2}$ inicial e $\mathrm{F}_{2}$ final) nos contextos percebidos como ditongados. Contudo, vogais não alongadas também apresentaram mudança de $\mathrm{F}_{2}$ (foram centralizadas), mesmo que o ingliding não tivesse sido percebido de oitiva. Concluímos, então, que o ingliding só é percebido de oitiva quando a vogal é também alongada. Vale dizer, é a soma dos processos - alongamento e mudança de $\mathrm{F}_{2}$ - o que gera o ingliding percebido de oitiva. Tome-se como exemplo a realização de uma mesma palavra, ibope, por essa falante prototípica, com e sem ingliding percebido de oitiva. No Quadro 1, estão os valores de duração, de $\mathrm{F}_{2}$ inicial e final das vogais tônicas nas duas realizações, para comparação.

Quadro 1 - Valores de duração, de $\mathrm{F}_{2}$ inicial e final das vogais em sílaba tônica de ib[Je] pe ibope

\begin{tabular}{|c|c|c|}
\hline & ib[je]pe & ibope \\
\hline Duração & $320 \mathrm{~ms}$ & $96 \mathrm{~ms}$ \\
\hline $\mathrm{F}_{2}$ inicial & $855 \mathrm{~Hz}$ & $1053 \mathrm{~Hz}$ \\
\hline $\mathrm{F}_{2}$ final & $1355 \mathrm{~Hz}$ & $1166 \mathrm{~Hz}$ \\
\hline Alongamento & $\mathrm{Sim}$ & Não \\
\hline Ingliding & $\mathrm{Sim}$ & Não \\
\hline
\end{tabular}

Fonte: Battisti e Oliveira (2014, p. 49).

$\mathrm{Na}$ realização de ibope sem ingliding, houve uma variação de $\mathrm{F}_{2}$ de $113 \mathrm{~Hz}$. Quando a variação é maior e tende à estabilidade nas porções inicial e final é que se tem o ingliding, como em ib/je]pe, com variação de $500 \mathrm{~Hz}$, associada à maior duração vocálica.

Verificamos a mudança de valores na curva de $\mathrm{F}_{2}$ rumo à centralização das diferentes vogais (aumento de $\mathrm{F}_{2}$ nas vogais posteriores / u o $\mathrm{J}$, diminuição de $\mathrm{F}_{2}$ nas vogais anteriores /i e $\varepsilon /$ ) tomando como parâmetro as médias de cada vogal em sua porção mais estável conforme a realização da própria falante prototípica, em contextos sem ingliding. A realização ib/je/pe começa com um valor de $\mathrm{F}_{2}$ mais baixo do que o valor médio de $/ \mathrm{o}$, fica relativamente estável na frequência esperada para a vogal média-baixa posterior e, ao final da realização, $\mathrm{F}_{2}$ alcança $1355 \mathrm{~Hz}$, bastante próximo da média de $\mathrm{F}_{2}$ da vogal / a/ nas realizações da falante prototípica, por volta de $1400 \mathrm{~Hz}$, e distante das vogais posteriores, com média próxima a $1100 \mathrm{~Hz}$. É essa centralização do valor de $\mathrm{F}_{2}$ na porção final da realização vocálica que soa como [e] a quem ouve o falar de porto-alegrenses com ingliding.

Pautados por principios da fonologia entoacional (LADD, 2008) e por achados de Frota (1998), verificamos que as realizações com ingliding ocorrem em seg-

\footnotetext{
Pitch é a altura relativa (ou tom) da voz conforme percebe o ouvinte. A altura tonal resulta do número de vezes que a onda sonora periódica complexa produzida pelas pregas vocais se repete por segundo (JOHNSON, 2012, p. 25), o que se capta acusticamente mediante controle da frequência fundamental (FO), medida em Hertz (Hz). Pitch é o principal correlato acústico do tom e da entonação. A fonologia entoacional (LADD, 2008, p. 64), baseada na teoria métrica autossegmental, usa os tons abstratos H (alto) e $L$ (baixo) com referência a níveis de pitch na realização fonética, verificados com medidas de Fo.
} 
mentos proeminentes em final de constituinte prosódico, frequentemente no final de frases entoacionais ${ }^{6}$ como no exemplo: [o jabá é um termo ant[ie]go] [ $\left.\left.n / \varepsilon e\right]\right]$ ${ }_{\mathrm{I}}$ [quer $\left.\operatorname{diz}[e e](r)\right]_{\mathrm{I}}$. Acusticamente, isso pode ser observado no exemplo a seguir, a realização $[h[o e] j e]_{I}$. Assim como na emissão de né, hoje aparece entre pausas relativamente longas, o que constitui uma frase entoacional. $\mathrm{Na}$ emissão com ingliding, de duração alta (340 ms), observam-se alterações de $\mathrm{F}_{2}$ associadas a movimentos de pitch.

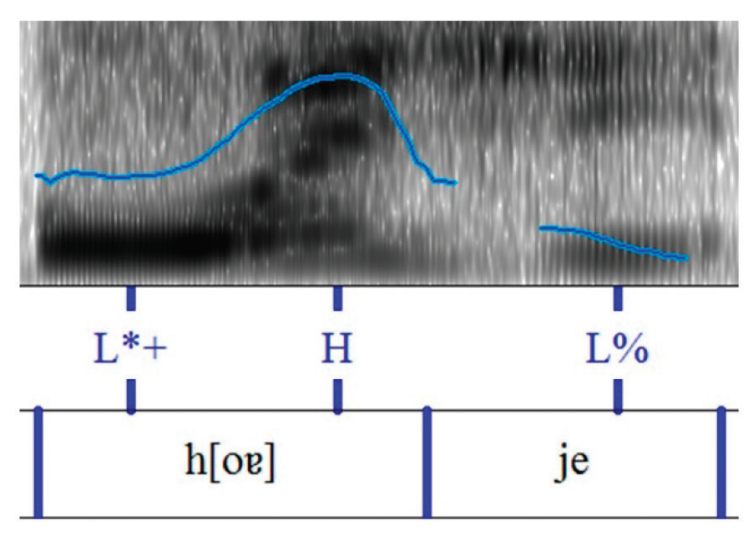

Figura 2 - Frequência fundamental $\left(\mathrm{F}_{0}\right)$ de $[\mathrm{h}[\mathrm{oe}] \mathrm{je}]_{\mathrm{I}}$ sobre espectrograma do PRAAT

Fonte: Elaborada pelos autores.

Na Figura 2, a ocorrência com ingliding apresenta uma curva de $\mathrm{F}_{0}$ que parece constituir um tom complexo $\mathrm{L}^{*}+\mathrm{H}$ seguido de um tom $\mathrm{L} \%$ de fronteira. Tal contorno tonal complexo $\left(\mathrm{L}^{*}+\mathrm{H}\right)$, um gliding tone, foi constatado nos demais casos de ingliding e pode ser efeito da marcação de constituinte prosódico, como a frase entoacional. Esse seria o princípio linguístico dirigindo alongamento e ingliding, a marcação de constituência prosódica.

\section{Percepção, avaliação e atitudes}

Oliveira (2015) realizou um estudo de percepção e avaliação do ingliding com alongamento vocálico (doravante apenas ingliding) e de atitudes ${ }^{7}$ em relação ao processo no português falado em Porto Alegre. Utilizou duas técnicas, de estímulos pareados ${ }^{8}$ (LAMBERT et al., 1960) e de mapas desenhados (PRESTON, 1989). O autor baseou a elaboração dos instrumentos - questionário e mapas - em Oushiro (2015) e Rosa (2014), respectivamente. Os instrumentos foram aplicados a oito participantes, nativos porto-alegrenses, sendo um do

\footnotetext{
6 A inicial de Intonational Phrase (Frase Entoacional), l, é usada subscrita aos colchetes que marcam esse constituinte prosódico.

7 A noção de atitude seguida no estudo implica percepção e avaliação de formas linguísticas. Conforme Edwards (2009, p. 83), atitude é entendida na psicologia social, em linhas gerais, como disposição a reagir favorável ou desfavoravelmente a uma classe de objetos. Tal disposição implica ter sentimentos (componente afetivo), pensamentos (componente cognitivo) e predispor-se a agir de uma certa forma (componente comportamental) em relação a essa classe de objetos.

8 Matched-guise technique, também comumente traduzida como "técnica dos falsos pares".
} 
sexo masculino e um do sexo feminino para cada uma das quatro zonas da cidade (Central, Norte, Leste e Sul) ${ }^{9}$.

$\mathrm{Na}$ técnica de estímulos pareados, estímulos, resultantes da leitura de um texto (no Anexo) em voz alta, foram produzidos por dois homens e duas mulheres, ora com ingliding, ora sem. O texto lido e gravado é uma adaptação de um trecho de fala da porto-alegrense prototípica (seção "Aspectos acústicos e entoacionais"). Após ouvir a gravação dos estímulos, os participantes responderam a um questionário com um conjunto de questões envolvendo variáveis continuas/quantitativas organizadas em diferenciais semânticos de cinco pontos, sendo 1 equivalente a pouco e 5 a bastante; e com um conjunto de questões envolvendo caixas de seleção com características pessoais que os participantes poderiam escolher, na quantidade que julgassem relevante (do total de trinta opções).

Os fatores constantes no questionário (em itálico), por questão, foram:

- (1.a) Para você, o falar dessa pessoa é: Agradável, Confortável (inteligivel) claro), Prestigiado.

- (1.b) Para você, essa pessoa parece: Extrovertida, Escolarizada, Inteligente, Feminina/Masculina, Formal, Amigável, Porto-alegrense, Ter sotaque, Ter amigos.

- (1.c) Essa pessoa deve morar num: Bairro mais periférico-Bairro mais central.

- (2) Considerando o que você ouviu, essa pessoa deve ser: Patricinha/Mauricinho, Trabalhadora, Preguiçosa, Sociável, Maconheira, Prática, Confiante, Religiosa, Deprimida, Gay/Lésbica, Simples, Confiável, Caipira, Conservadora, Solidária, Mimada, Tímida, Mal-educada, Engraçada, Independente, Sofisticada, Negra, Branca, Articulada, Nerd, Metida, Desencanada, Irritante, Descolada, Sincera.

Alguns resultados da análise, feita com o software SPSS ${ }^{10}$, são apresentados nas tabelas 1 e 2. A Tabela 1 refere-se à avaliação do estímulo produzido por uma mulher, sem e com ingliding (colunas da esquerda e da direita abaixo de cada fator, respectivamente). A Tabela 2 refere-se à avaliação do estímulo produzido por um homem. regioes_atendimento_cores.jpg>. Acesso em: 19 mar. 2016.

10 Statistical Package for Social Sciences, pacote de programas estatísticos empregados em ciências humanas e sociais. Disponível em: <www. spss.com>. Acesso em: 10 abr. 2016. 
Tabela 1 - Resultados do questionário de percepção e avaliação para o estímulo $\mathrm{R}($ feminino), sem (coluna da esquerda) e com (coluna da direita) ingliding

\begin{tabular}{|c|c|c|c|c|c|c|c|c|c|c|c|c|c|c|}
\hline \multicolumn{3}{|c|}{ Participantes } & \multicolumn{12}{|c|}{ Fatores: sem | com ingliding } \\
\hline \multirow{2}{*}{\begin{tabular}{|c|}
$\mathbf{N}^{\mathbf{o}}$ \\
1
\end{tabular}} & \multirow{2}{*}{$\begin{array}{r}\text { Sexo } \\
M\end{array}$} & \multirow{2}{*}{\begin{tabular}{|c|} 
Zona \\
Central
\end{tabular}} & \multicolumn{2}{|c|}{ Agradável } & \multicolumn{2}{|c|}{ Confortável } & \multicolumn{2}{|c|}{ Prestigiado } & \multicolumn{2}{|c|}{ Formal } & \multicolumn{2}{|c|}{$\begin{array}{c}\text { Porto- } \\
\text {-Alegrense }\end{array}$} & \multicolumn{2}{|c|}{ Ter sotaque } \\
\hline & & & 4 & 2 & 5 & 4 & 4 & 3 & 5 & 3 & 4 & 5 & 4 & 5 \\
\hline 2 & $\mathrm{~F}$ & Central & 3 & 2 & 5 & 5 & 3 & 3 & 5 & 2 & 1 & 5 & 1 & 5 \\
\hline 3 & M & Norte & 5 & 1 & 5 & 4 & 3 & 3 & 4 & 3 & 3 & 5 & 1 & 1 \\
\hline 4 & $\mathrm{~F}$ & Norte & 2 & 2 & 2 & 2 & 3 & 3 & 3 & 3 & 4 & 4 & 3 & 4 \\
\hline 5 & M & Sul & 4 & 4 & 5 & 3 & 3 & 3 & 5 & 4 & 2 & 5 & 3 & 3 \\
\hline 6 & $\mathrm{~F}$ & Sul & 3 & 4 & 5 & 5 & 1 & 3 & 5 & 4 & 1 & 5 & 1 & 4 \\
\hline 7 & M & Leste & 3 & 4 & 4 & 3 & 4 & 3 & 3 & 4 & 4 & 3 & 1 & 3 \\
\hline 8 & $\mathrm{~F}$ & Leste & 3 & 2 & 4 & 3 & 4 & 1 & 5 & 3 & 4 & 4 & 4 & 4 \\
\hline \multicolumn{3}{|c|}{ Médias } & 3,37 & 2,62 & 4,37 & 3,62 & 3,12 & 2,75 & 4,37 & 3,25 & 2,87 & 4,5 & 2,25 & 3,62 \\
\hline \multicolumn{3}{|c|}{ Significância } & \multicolumn{2}{|c|}{0,244} & \multicolumn{2}{|c|}{0,02} & \multicolumn{2}{|c|}{0,476} & \multicolumn{2}{|c|}{0,038} & \multicolumn{2}{|c|}{0,048} & \multicolumn{2}{|c|}{0,036} \\
\hline
\end{tabular}

Fonte: Oliveira (2015, p. 364).

Tabela 2 - Resultados do questionário de percepção e avaliação para o estímulo $\mathrm{M}$ (masculino), sem (coluna da esquerda) e com (coluna da direita) ingliding

\begin{tabular}{|c|c|c|c|c|c|c|c|c|c|c|c|c|c|c|}
\hline \multicolumn{3}{|c|}{ Participantes } & \multicolumn{12}{|c|}{ Fatores: sem | com ingliding } \\
\hline \multirow{2}{*}{\begin{tabular}{|c|}
$\mathbf{N}^{\circ}$ \\
1
\end{tabular}} & \multirow{2}{*}{\begin{tabular}{|r|} 
Sexo \\
$M$
\end{tabular}} & \multirow{2}{*}{$\begin{array}{c}\text { Zona } \\
\text { Central }\end{array}$} & \multicolumn{2}{|c|}{ Agradável } & \multicolumn{2}{|c|}{1 Confortável } & \multicolumn{2}{|c|}{ Prestigiado } & \multicolumn{2}{|c|}{ Formal } & \multicolumn{2}{|c|}{$\begin{array}{c}\text { Porto- } \\
\text {-Alegrense }\end{array}$} & \multicolumn{2}{|c|}{ Ter sotaque } \\
\hline & & & 4 & 3 & 5 & 4 & 4 & 3 & 4 & 3 & 5 & 5 & 3 & 5 \\
\hline 2 & $\mathrm{~F}$ & Central & 5 & 3 & 4 & 4 & 4 & 3 & 5 & 2 & 2 & 4 & 1 & 4 \\
\hline 3 & M & Norte & 4 & 2 & 5 & 5 & 4 & 3 & 5 & 3 & 5 & 5 & 1 & 1 \\
\hline 4 & $\mathrm{~F}$ & Norte & 4 & 4 & 4 & 4 & 3 & 4 & 3 & 3 & 4 & 5 & 4 & 5 \\
\hline 5 & M & Sul & 3 & 4 & 3 & 4 & 4 & 5 & 4 & 4 & 2 & 5 & 3 & 5 \\
\hline 6 & $\mathrm{~F}$ & Sul & 4 & 4 & 4 & 4 & 2 & 4 & 3 & 2 & 4 & 4 & 3 & 3 \\
\hline 7 & M & Leste & 3 & 3 & 3 & 3 & 4 & 3 & 4 & 3 & 3 & 3 & 3 & 4 \\
\hline 8 & $\mathrm{~F}$ & Leste & 5 & 3 & 5 & 3 & 4 & 2 & 4 & 2 & 4 & 3 & 3 & 4 \\
\hline \multicolumn{3}{|c|}{ Médias } & 4 & 3,25 & 4,12 & 3,87 & 3,62 & 3,37 & 4 & 2,75 & 3,62 & 4,25 & 2,62 & 3,87 \\
\hline \multicolumn{3}{|c|}{ Significância } & \multicolumn{2}{|c|}{0,111} & \multicolumn{2}{|c|}{0,451} & \multicolumn{2}{|c|}{0,25} & \multicolumn{2}{|c|}{0,011} & \multicolumn{2}{|c|}{0,217} & \multicolumn{2}{|c|}{0,011} \\
\hline
\end{tabular}

Fonte: Oliveira (2015, p. 364-365). 
A grande diferença entre as médias no fator porto-alegrense mostrou que, para a maioria dos participantes, o falar com ingliding é típico de Porto Alegre. Os fatores agradável, confortável e prestigiado tiveram resultados variados, o que sugere não haver acordo na avaliação do falar marcado pelo processo. Os fatores formal e ter sotaque revelaram-se estatisticamente significativos: o falar com ingliding foi relacionado ao de alguém menos formal e com sotaque. As características mais frequentemente selecionadas para a oposição entre os dois falares foram: desencanado, descolado e preguiçoso, para o falar com ingliding; e trabalhador, nerd e conservador, para o falar não marcado pelo processo.

Na técnica de mapas desenhados, os informantes foram solicitados a marcar, conforme sua percepção, áreas de Porto Alegre em que as pessoas possuíssem um jeito diferente de falar, podendo essa diferença ser de qualquer tipo. Além de localizar no mapa, os informantes deveriam registrar características dos falares mencionados. Os informantes recebiam um mapa em branco da cidade de Porto Alegre (ROSA, 2014, p. 72), com alguns pontos turísticos de referência, e um mapa com bairros vigentes como fonte de consulta (ROSA, 2014, p. 73).

Três áreas foram recorrentemente desenhadas pelos informantes: centro, que é a área mais antiga da cidade, onde Porto Alegre foi inicialmente habitada e de onde se expandiu; sudeste, onde se localiza o bairro Restinga ${ }^{11}$, fundado nos anos 1970 para acolher famílias inscritas em programas de habitação popular; extremo sul, onde há pequenas propriedades rurais, de produção agroecológica e de criação de cavalos e ovelhas ${ }^{12}$. É o que se vê na Figura 3, adaptada do ObservaPOA ${ }^{13}$, que mapeia a cidade conforme a renda do responsável pela familia, tomando como parâmetro dez salários mínimos. A escala em cinco graus, que vai de melhores a piores, passando por intermediárias, avalia em que medida o salário do responsável aproxima-se de/supera (melhores) ou afasta-se de/é inferior a (piores) dez salários mínimos. A associação entre área dialetal e renda sugere haver uma relação entre estrato socioeconômico e os falares identificados pelos participantes.

Legenda 1: ObservaPOA

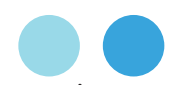

melhores - intermediárias - piores

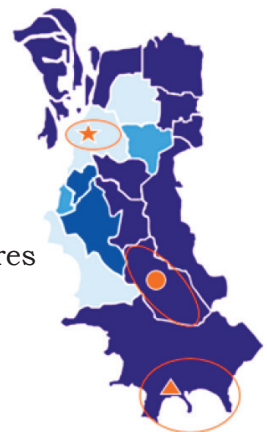

Legenda 2: Mapas desenhados

$\star$ Centro de Porto Alegre

fala cantada, arrastada, descansada

- Sudoeste de Porto Alegre

fala menos cantada, com muitas gírias

- Extremo sul de Porto Alegre

fala não cantada, de zona rural

Figura 3 - Mapa de Porto Alegre adaptado do ObservaPOA, com indicação de áreas conforme a renda do responsável pela família, tendo como parâmetro dez salários mínimos (legenda 1) e regiões apontadas por participantes no instrumento de mapas desenhados (legenda 2).

Fonte: Adaptada de ObservaPOA (legenda 1) por Oliveira (2015, p. 371) (legenda 2).

\footnotetext{
Disponível em: <http://portoalegreemanalise.procempa.com.br/?regioes=93,0,0>. Acesso em: 9 abr. 2016.

Disponível em: <www.caminhosrurais.com.br>. Acesso em: 9 abr. 2016.

3 O Observatório da Cidade de Porto Alegre (ObservaPOA) levanta e disponibiliza informações georreferenciadas sobre o município de Porto Alegre. Disponível em: <http://www.observapoa.com.br/>. Acesso em: 9 abr. 2016.
} 
Vale destacar que o centro da cidade foi associado ao falar com ingliding referido como "sotaque porto-alegrense" e "fala cantada", "arrastada" e "descansada" - principalmente por porto-alegrenses que frequentam a zona com alguma regularidade e gostam do centro. Parece haver uma associação entre o processo e regiões que gozam de bons níveis econômicos, ou entre o falar com ingliding e status social, levando em conta tanto fatores objetivos (como renda) quanto subjetivos (como hábitos de consumo, acesso a bens culturais, opções de lazer etc.). Vale notar, também, que moradores da zona central atuam nas mídias da cidade, como é o caso da falante prototípica cujos dados de fala receberam análise acústica (seção "Aspectos acústicos e entoacionais"). Isso contribui para que o padrão de fala desses agentes culturais se difunda e seja simbolicamente tomado como modelo de falar porto-alegrense.

Os resultados de Oliveira (2015) sugerem que uma variável como o ingliding não possui significados estáticos, mas significados gerais que se especificam em certos contextos estilístico-ideológicos. Essa é a ideia de campo indexical de Eckert (2008), abordada na seção seguinte e tomada como fundamento de nossa proposta de significados potenciais do ingliding.

\section{Significado social da variação lingúistica: A PROPOSTA DE ECKERT (2008)}

Eckert (2008) defende que o foco dos estudos de variação deve estar em seu significado social e propõe, para tanto, um modelo dinâmico baseado no conceito de campo indexical que, por sua vez, deriva do conceito de ordem indexical de Silverstein (2003). Para Eckert (2008), o estudo do significado social da variação linguística deve se basear em um estudo da prática estilística e considerar que as variáveis indexam categorias demográficas indiretamente, por meio de sua associação a qualidades e instâncias que fazem parte da construção dessas categorias.

O objetivo da autora não é anular o método de estudo baseado em categorias demográficas diante do outro, mas utilizá-los de maneira complementar, já que a prática estilística, definida como negociação, interpretação e produção de estilos, está intrinsecamente ligada à ordem social mais ampla. Eckert (2008) defende que o favorecimento do uso de uma variante por determinada categoria macrossocial não deve ser encarado de maneira fixa, como mero reflexo na variação linguística, mas como recurso para construção do significado social, o que aponta para a necessidade de uma análise do que está por trás das generalizações: a construção e manutenção de identidades em comunidades de prática.

Levando em consideração a ideia de que variáveis cujos usos já estejam no nível da consciência dos falantes combinam-se para construir estilos, Eckert (2008, p. 454) propõe que:

[...] os significados das variáveis não são precisos ou fixos, mas constituem um campo de significados potenciais - um campo indexical, ou constelação de significados ideologicamente relacionados, qualquer um dos quais pode ser ativado no uso situado da variável ${ }^{14}$.

14 "[...] the meanings of variables are not precise or fixed but rather constitute a field of potential meanings - an indexical field, or constellation of ideologically related meanings, any one of which can be activated in the situated use of the variable". 
O campo indexical é fluido e dinâmico por estar em constante processo de reinterpretação. Vale dizer, o significado das variáveis não será uniforme através da população, mas sensivel à perspectiva dos sujeitos, aos contextos, a identidades e estilos que emergem em comunidades de prática. Os movimentos estilísticos são sempre ideológicos e os campos indexicais, baseados em significados potenciais, são relativos.

Para Silverstein (2003), um indice de primeira ordem - que se assemelha ao conceito laboviano de indicador - torna-se um indice de segunda ordem - semelhante ao conceito laboviano de marcador - quando o resultado da avaliação social dos falantes que empregam determinadas formas passa a ser associado às próprias formas. Os índices de Silverstein (2003) diferem dos conceitos de Labov (2008 [1972]) porque admitem reinterpretação (indexação de novos significados) conforme o uso em diferentes práticas sociais, ideia tomada como base na concepção de campo indexical de Eckert (2008), que o vê como algo fluido e dinâmico.

Um dos exemplos de campo indexical fornecidos por Eckert (2008) baseia-se nos resultados do teste de percepção de Campbell-Kibler (2007a, 2007b apud ECKERT, 2008) sobre as associações feitas pelos ouvintes à pronúncia velar ou apical da nasal do morfe -ing, em formas como playing ('jogando'), going ('indo'). A Figura 4, que representa esse campo, traz as associações com a pronúncia velar em preto, e com a pronúncia apical em cinza ${ }^{15}$.

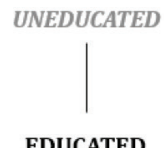

EDUCATED

RELAXED — FORMAL

EFFORTFUL — EASYGOING/LAZY

ARTICULATE/PRETENTIOUS

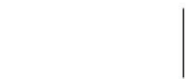

INARTICULATE/UNPRETENTIOUS

Figura 4 - Campo indexical de (ING)

Fonte: Eckert (2008, p. 466).

A autora toma o cuidado de reafirmar que este é apenas um campo indexical possivel, ou seja, com significados potenciais, não fixos. Os significados são relativos e a seleção de quais significados do campo indexical apresentado serão associados a dadas ocorrências depende, segundo a autora, da perspectiva do ouvinte e do estilo corporificado pelo falante na realização de certas práticas sociais, o que inclui não apenas a forma linguística do enunciado, mas seu con-

Os equivalentes em português aos termos educated, effortful, articulate/pretentious, formal são, respectivamente, escolarizado, esforçado, articulado/pretensioso, formal. Os equivalentes aos termos uneducated, easygoing/lazy, inarticulate/unpretentious, relaxed são, respectivamente, não escolarizado, tranquilo/preguiçoso, desarticulado/despretensioso, descontraído. 
teúdo. Os pares não devem, portanto, ser tomados como oposições fixas. Um exemplo disso é, como se vê na Figura 4, o contrário de um sujeito "esforçado" (effortful), que pode ser a avaliação negativa "preguiçoso" (lazy) ou a avaliação positiva "tranquilo" (easygoing). Embora os significados estejam ideologicamente relacionados, não há preocupação, nesse campo indexical, em representar como ou quanto os termos se associam ou se afastam entre si, como fez Oushiro (2015) em seu modelo de Árvore de Distâncias Mínimas, uma exploração menos impressionística da noção de campo indexical de Eckert (2008). Tampouco nós quantificaremos a distância de associação das avaliações, se mais próxima ou mais afastada. Centraremos atenção na gama de significados potenciais do ingliding e na possivel associação entre eles num campo indexical, como veremos a seguir.

\section{Significados sociais do ingliding No PORTUGuês Falado EM Porto Alegre: uma PROPOSTA DE CAMPo INDEXICAL}

Que valor social tem o ingliding no português falado em Porto Alegre? Tanto a exploração preliminar de opiniões sobre o falar de Porto Alegre (BATTISTI, 2013) quanto o estudo de percepção, avaliação e atitudes (OLIVEIRA, 2015) mostraram que o ingliding não porta um valor, apenas. As avaliações sugerem que o ingliding possua uma gama de significados potenciais, construídos e interpretados mediante o uso dessa variável em certas práticas sociais. Criam-se personas ${ }^{16}$ mobilizando-se ingliding (ou sua não realização) e significados relacionados, constituidores de um campo indexical. Tal campo é o que se representa na Figura 5.

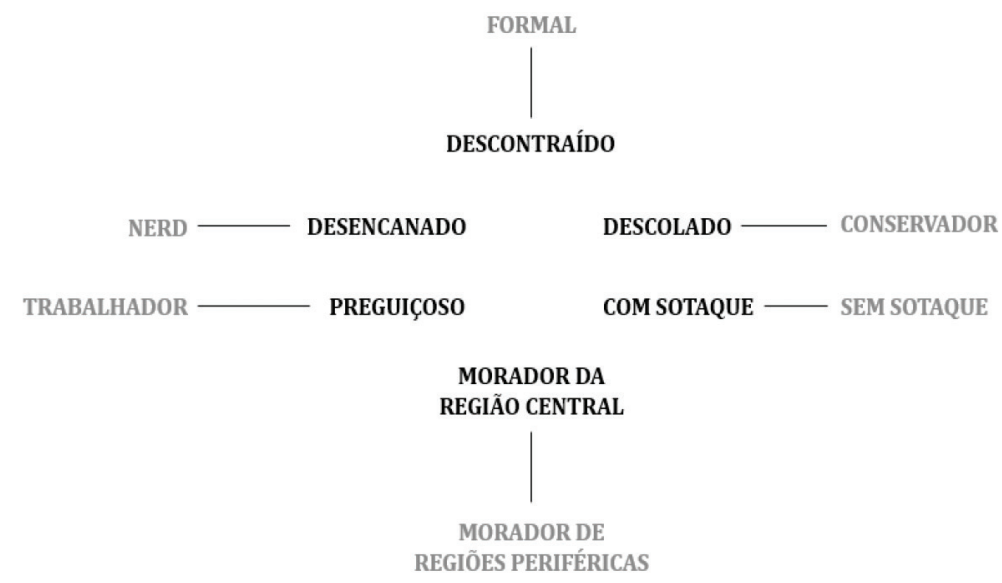

Preto $=$ significados associados à presença de ingliding.

Cinza $=$ significados associados à ausência de ingliding

Figura 5 - Campo indexical do ingliding no português de Porto Alegre (RS)

Fonte: Elaborada pelos autores. 
Os termos em preto e cinza na Figura 5 não são oposições semânticas. Em preto estão termos correspondentes a fatores que, explorados por Oliveira (2015), mostraram-se significativos no estudo de percepção, avaliação e atitudes do ingliding no português falado em Porto Alegre. Os termos em cinza correspondem a significados que, por contraste, podem ser ideologicamente associados à não realização do processo. É o que se verificou com a técnica de estímulos pareados: os estímulos produzidos sem ingliding pelos falantes foram associados aos termos em cinza. Quando os falantes introduziram ingliding no estímulo, tiveram seus falares avaliados pelos termos em preto.

O campo indexical que propomos (Figura 5), lido a partir dos termos em preto, representa o falar marcado pelo ingliding. Os termos em cinza sustentam-se na ideia de que a presença desse traço linguístico é capaz de alterar expressivamente os significados construídos, mudar a persona ou o papel que, interpretamos, o falante esteja desempenhando numa dada situação social, na realização de certas práticas sociais. O ingliding pode indexar tanto um modo de ser ou estilo de vida - descontraído, desencanado, descolado e preguiçoso - quanto o local, na cidade, onde mora o falante - centro da cidade. A presença de com sotaque no campo revela que a variável pode indexar, ainda, uma diferença (estilístico-ideológica) entre falantes, muito provavelmente identificadora de grupos ou categorias macrossociais a que eles pertencem.

A tríade estilo de vida, local de residência e estrato social a que pertence o falante, sobre a qual se assenta o campo indexical do ingliding no português falado em Porto Alegre, corresponde ao que está presente nas respostas aos diferentes testes conduzidos e, de forma exagerada, em estereótipos de porto-alegrenses, como o magrão. Nesse sentido, a mídia (rádio, TV, cinema) contribui não só para difundir a variável, mas também para alimentar e consolidar personas que, com ingliding e outros recursos linguísticos e não linguísticos, têm no estilo informal, despojado, descolado seus traços principais.

A falante prototípica cujos dados linguísticos analisamos acusticamente (seção "Aspectos acústicos e entoacionais") é exemplo da projeção de personas preferidas que, conforme Coupland (2007, p. 150), se espera de locutores de rádio. Antes de seu self ${ }^{17}$ real, essa porto-alegrense, comunicadora de rádio, projeta e confere autenticidade a uma persona relativa às expectativas do veículo de comunicação e, principalmente, dos consumidores dos produtos desse veículo, os ouvintes. Para isso, faz uso de traços de fala, alguns deles extravagantemente exagerados, para indexar significados sociais. Numa entrevista ${ }^{18}$ concedida por ela e demais comunicadores de uma rádio que, na cena cultural porto-alegrense dos anos $1980^{19}$, despontou por seu perfil jovem e inovador - a rádio Ipanema FM, pronunciada Ipan[ee]ma, com ingliding -, conseguimos identificar alguns elementos ideológicos ligados a características linguísticas. "No início, a gente era a única rádio rock", afirma um dos entrevistados. Outro completa: “[...] [ela] nunca foi atrás do

\footnotetext{
17 Empregamos a noção de self como fazem os antropólogos. Para eles, conforme Foley (1997, p. 262-263), self é a consciência que todos temos de nossa individualidade. Diferentemente, pessoa é um conceito social, baseado em noções locais de direitos e deveres, portanto variável nas diferentes culturas.

18 Disponível em: <http://jackoldpunk.blogspot.com.br/2013/08/a-historia-da-radio-ipanema-fm.html>. Acesso em: 13 abr. 2016

19 Numa das etapas da pesquisa voltada à percepção do português porto-alegrense e a distribuição de possíveis subvariedades no espaço geográfico da cidade, houve depoimentos de que o ingliding (referido como "cantado", "vogais alongadas") surgiu nos anos 1980 , no bairro Bom Fim e adjacências, centro de Porto Alegre. Nesse período, o traço, que possivelmente já estava presente na fala da comunidade, deve ter ganhado saliência. Nessa mesma época, situam-se personagens como o Magro do Bonfa, interpretado pelo humorista gaúcho André Damasceno (disponível em: <https://www.youtube.com/watch?v=B2icczA-13s>. Acesso em: 15 abr. 2016).
} 
modismo. A Ipanema correu na frente, então a gente sempre mostrou antes pra todo mundo, não tendo medo do novo nunca". A concepção dos entrevistados é a de terem atuado numa rádio inovadora, que tocava o que não era habitual nas emissoras concorrentes, e novidade no cenário musical brasileiro e mundial. "A gente é responsável pela formação musical de uma geração", afirma nossa falante prototípica, uma das comunicadoras. Além do caráter inovador da rádio, que a diferenciava das demais, a persona dos comunicadores da Ipanema era distinta: "A Continental [rádio concorrente] era muito satírica e engraçadinha, e a gente era simplesmente irônico com uma tendência ao ranço, até mais mal-humorado. $\mathrm{E}$ a Continental não, era humorada, mais aberta, e nós, carrancudos". O caráter "rançoso" referido pelo comunicador correspondia à forma crítica com que cumpriam funções da rádio: "[...] ela tinha de divulgar as bandas, os músicos gaúchos da MPG [Música Popular Gaúcha], tinha que dar notícias”. Essa última função, a da divulgação de notícias, que se fazia pela leitura de material dos jornais locais Zero Hora, Folha da Tarde e, de São Paulo, a coluna de articulistas como Paulo Francis, por exemplo, rendeu um comentário de nossa falante prototípica possivelmente ligado ao ingliding e a características da fala de sua persona comunicadora: com "fundo musical e uma linguagem crítica e irônica, bem legal [...] eu lia bem devagarinho. Eu falava bem devagar e as pessoas achavam que eu (es)tava drogada. Eu ria". Uma fala mais vagarosa, "arrastada", propicia imprimir maior duração às vogais, principalmente as tônicas, de que o ingliding emerge. Depoimentos como esse, de nossa falante prototípica, respaldam não só os significados do campo indexical aqui proposto (Figura 5), mas também confirmam a ideia de que ingliding seja uma variável sociolinguística recrutada para indexar estilos e certos significados sociais, principalmente a partir dos anos 1980, para a projeção de personas inovadoras, descoladas, despojadas, mesmo fora do cenário institucional (rádio) e distante dos meios de produção e difusão cultural.

O campo indexical na Figura 5, então, é um campo de significados potenciais para a variável em questão. Por ser relativo e fluido, como propõe Eckert (2008), os significados que cada falante e ouvinte selecionarão e atribuirão ao ingliding dependerão da perspectiva dos interlocutores e do estilo que incorporam, por sua vez relacionados às comunidades de prática que os sujeitos integram. Os dados de Oliveira (2015) já indicam essa fluidez e possibilidade de reinterpretação: nem todos os informantes relacionaram as mesmas características ao falar com ingliding e alongamento: o significado morador de bairro central, por exemplo, foi atribuído por pessoas que moram ou frequentam e gostam do centro da cidade. Os significados mais regulares, de acordo com análise de significância dos dados de todos os informantes - e que, portanto, possuiriam mais possibilidade de figurar nos campos indexicais acessados pelos sujeitos -, dizem respeito à formalidade (descontraido) e presença de sotaque (com sotaque).

\section{ConClusão}

A análise que fizemos dos significados sociais do ingliding de vogais tônicas no português de Porto Alegre mostrou a gama de associações que se podem estabelecer com o uso da variável ou, por contraste, com sua não realização. Descolado, descontraido, desencanado, preguiçoso, com sotaque, morador da área central da cidade fazem parte de um campo indexical fluido, que pode ser (re)interpretado a cada uso da linguagem. 
Explorar os significados sociais do ingliding na forma de um campo indexical, como fizemos, permitiu abordar uma variável que, no português falado em Porto Alegre, não faz parte de mudança em progresso e que, talvez por essa razão, não desperte interesse do ponto de vista estrutural. Sobre isso, Eckert (2008, p. 472) afirma:

Infelizmente, essas variáveis não terão sido incluidas em grandes estudos de comunidade [de fala], então nós não nos beneficiaremos do tipo de informação macrossociológica sobre elas de que nos beneficiamos para as variáveis mais comumente estudadas ${ }^{20}$.

O ingliding, que ainda não foi contemplado em estudos voltados à comunidade de fala e ao estabelecimento de correlação da variável com categorias sociais mais amplas, será por nós incluído num estudo em larga escala, que se tornará possivel à medida que se realizarem as entrevistas sociolinguísticas em Porto Alegre e a amostra de fala se constituir. Estamos envolvidos nessa tarefa no momento. Além disso, há a perspectiva de ampliar o teste de avaliação/atitudes, contando com um número maior de participantes. Esperamos que as futuras análises revelem o padrão de ingliding do ponto de vista linguístico, em seus aspectos segmentais e prosódicos, e do ponto de vista extralinguístico, no que diz respeito à sua relação com aspectos da organização social da comunidade, prestando assim alguma contribuição às teorias voltadas ao significado social da variação linguística.

\section{Social meanings of inglided stressed vowels in Brazilian Portuguese spoken in Porto Alegre (RS)}

Abstract: This paper is about the social meanings of stressed vowels with ingliding (voc[e] voc[ee], aqu[i] aqu[ie]) in the Portuguese spoken in Porto Alegre, Rio Grande do Sul state, Brazil. The analysis follows Eckert (2008) and shows that the meanings descolado "smart", descontraido "relaxed", desencanado "carefree", preguiçoso "lazy", com sotaque "with an accent", morador da área central da cidade "inhabitant of the city center" of the inglided forms are part of a fluid indexical field, subject to (re)interpretation at every language use.

Keywords: Language variation. Ingliding. Indexical field.

\section{REFERÊNCLAS}

BATTISTI, E. Realizações variáveis de vogais tônicas em Porto Alegre (RS): ditongação ou ingliding? Fragmentum, Santa Maria, n. 39, p. 58-76, out./dez. 2013.

BATTISTI E; OLIVEIRA, S. Alongamento e ingliding de vogais em sílabas tônicas no português falado em Porto Alegre (RS). Revista (Con)Textos Linguisticos, Vitória, v. 8, n. 11, p. 39-56, 2014.

20 "Sadly, these variables will not have been included in large community studies, so we will not benefit from the kind of macrosociological information about them that we do for the more commonly studied variables". 
CLEMENTS, G. N.; HERTZ, S. R. An integrated approach to phonology and phonetics. In: DURAND, J.; LAKS, B. (Ed.). Current trends in phonology. Salford: University of Salford Publications, 1996.

COUPLAND, N. Style: language variation and identity. Cambridge: Cambridge University Press, 2007.

DONEGAN, P. J. On the natural phonology of vowels. 1978. PhD Dissertation, Graduate School of the Ohio State University, 1978.

ECKERT, P. Variation and the indexical field. Journal of Sociolinguistics, v. 12, n. 4, p. 453-476 2008.

EDWARDS, J. Language and identity. Cambridge: Cambridge University Press, 2009.

FOLEY, W. A. Antropological linguistics: an introduction. Malden; Oxford: Blackwell, 1997.

FROTA, S. Prosody and focus in European Portuguese. 1998. Tese (Doutorado em Letras)-Universidade de Lisboa, Lisboa, 1998.

JOHNSON, K. Acoustic and auditory phonetics. 3. ed. Malden; Oxford: WileyBlackwell, 2012.

INSTITUTO BRASILEIRO DE GEOGRAFIA E ESTATÍSTICA. Rio Grande do Sul - Porto Alegre. Disponivel em: <http://cidades.ibge.gov.br/xtras/perfil. php?codmun=431490>. Acesso em: 3 abr. 2016.

LABOV, W. Padrões sociolinguísticos. Tradução Marcos Bagno, Maria Marta Pereira Scherre e Caroline R. Cardoso. São Paulo: Parábola, 2008 [1972].

LABOV, W.; ASH, S.; BOBERG, C. The Atlas of North American English (ANAE). Berlin; New York: Mouton The Gruyter, 2006.

LADD, D. R. Intonational phonology. 2. ed. Cambridge: Cambridge University Press, 2008.

LAMBERT, W. et al. Evaluational reactions to spoken languages. Journal of Abnormal and Social Psychology, v. 60, n. 1, p. 44-51, Jan. 1960.

OLIVEIRA, S. G. O estereótipo do falar porto-alegrense: percepções e atitudes sobre o falar com ingliding e alongamento vocálico. In: FÓRUM FAPA, 14., 2015, Porto Alegre. Resumos... Porto Alegre: Fapa, 2015.

OUSHIRO, L. Identidade na pluralidade: avaliação, produção e percepção linguística. 2015. 372 f. Tese (Doutorado em Semiótica e Linguística Geral)-Departamento de Linguística, Universidade de São Paulo, São Paulo, 2015.

PRESTON, D. Perceptual dialectology: nonlinguists' views of areal linguistics. Dordrecht; Providence: Foris Publications, 1989.

ROSA, R. A comunidade de fala de Porto Alegre no estudo da variação linguística: identificando subcomunidades. 2014. Trabalho de Conclusão de Curso (Licenciatura em Letras)-Instituto de Letras, Universidade Federal do Rio Grande do Sul, Porto Alegre, 2014.

SILVERSTEIN, M. Indexical order and the dialectics of sociolinguistic life. Language and Communication, v. 23, n. 3-4, p. 193-229, July/Oct. 2003.

WENGER, E. Communities of practice: learning, meaning and identity. Cambridge: Cambridge University Press, 1998. 


\section{ANEXO}

Texto lido na gravação dos estímulos usados no estudo de Oliveira (2015).

Grifadas (negrito e sublinhado) estão as vogais produzidas com ingliding nos estímulos caracterizados pelo processo. O símbolo \# marca pontos do enunciado em que pausas foram produzidas em todos os estímulos.

As rádios operavam, \# e ainda operam, \# num formato chamado top quarenta. \# Esse formato é um formato americano \# e o nome já diz túdo. \# Toda \# a diversidade musical, \# os milhares de discos lançados anualmente, \# se reduzem \# a quarenta títulos, \# quarenta canções que são rodadas \# sendo repetidas \# com pesos muito bem marcados, \# nada é aleatório.

Recebido em abril de 2016. Aprovado em julho de 2016. 